\title{
ОПЫТ НАБЛЮДЕНИЯ ПАЦИЕНТОВ С САХАРНЫМ ДИАБЕТОМ И ТУБЕРКУЛЕЗОМ
}

\author{
Маклакова Т.П., Анюткина Т.И., Васильева Н.И., Ханин А.Л. \\ НГИУВ — филиал ФГБОУ ДПО РМАНПО МЗ РФ, Новокузнецк
}

В Сибирском регионе сохраняется напряженная эпидемиологическая ситуация по туберкулезу (ТБ). На примере г. Новокузнецка за последний год заболеваемость 83 случая на 100000 населения, в 2 раза превышающая среднероссийские показатели. Сахарный диабет (СД) и ТБ - наиболее опасная комбинация в связи с системностью их поражения, клиническим полиморфизмом и длительным бессимптомным течением. При СД ТБ выявляется в 4-11 раз чаще, чем в популяции; при СД 1 типа (СД-1) - в 20 раз чаще. Особую тревогу вызывает ВИЧ-ассоциированный ТБ, с частотой 58,6\% в структуре впервые выявленного ТБ по Новокузнецку.

ЦЕЛЬ РАБОТЫ - ИзУчить особенности Клинического течения и лечения СД у 39 пациентов С ТБ, пролеченных стационарно в Новокузнецком клиническом противотуберкулезном диспансере за последний год (3\% от госпитализированных). В наблюдаемой группе с СД 1 и СД 2 было 10 (26\%) и 29 (74\%) человек, соотношение женщин и мужчин 1: 1,5.

ВИЧ-ассоциированный ТБ при СДустановлен в 23\% (9 чел.): при СД-1 60\% (6 чел.) и при СД-2 10\% (3 чел.). Средний возраст пациентов с СД-1 не превышал 40 лет, а с СД-2 был старше 45 лет. По литературным данным, СД в 80-90\% предшествует диагностике ТБ и только в 18-20\% отмечается одновременное выявление патологии или ТБ диагностируется до выявления СД. В нашем наблюдении только в 54\% (21 чел.) диагноз СД установлен до клинического дебюта ТБ; в 41\% (16 чел.) оба заболевания диагностированы одновременно, в 5\% (2 чел.) ТБ предшествовал развитию СД. Столь заметные различия, вероятно, обусловлены поздней диагностикой СД, в основном, СД-2, клиническое проявление которого связано с присоединением инфекции. В 41\% случаев (16 чел.) наблюдался инфильтративный ТБ; в 46\% диссеминированный и кавернозный (18 чел.); в 10\% (4 чел.) экссудативный плеврит и в 5\% (2 чел.) туберкуломы. Преобладала нижнедолевая локализация процесса. Каждый 2-й пациент был бактериовыделителем независимо от типа СД. При поступлении в стационар у $87 \%$ пациентов отсутствовал контроль СД (гликемия 11-27 ммоль/л и выше). Все пациенты с СД-2 переводились на инсулинотерапию (базис-болюсный вариант). Во время химиотерапии ТБ основная проблема - побочные действия препаратов со стороны ЖКТ, печени и почек у 77\% (30 чел.) против 48\% у пациентов без СД. Всем пациентам с СД1 усилена инсулинотерапия на 20-70\% от привычной дозы, при СД-2 потребность в инсулине составляла 1,3-1,8 ЕД/кг/м.т. с выраженной вариабельностью гликемии независимо от типа СД. Несмотря на постоянную коррекцию лечения СД у 87 \% (34 чел.) пациентов не достигались целевые показатели. К особенностям терапии СД во время химиотерапии ТБ относится стойкость гипергликемии, ее вариабельность без склонности к кетоацидозу. Наибольшие трудности в лечении СД наряду с медленной инволюцией воспаления, длительным абациллированием отмечены у пациентов с ВИЧ-ассоциированным ТБ, а также у всех пациентов с множественной лекарственной устойчивостью возбудителя.

Выход из сложившегося положения возможен при своевременной диагностике обоих заболеваний и усилении мотивации пациентов на достижение целевых результатов терапии; раннем выявлении скрытых нарушений углеводного обмена при наличии факторов риска развития СД и ТБ. 